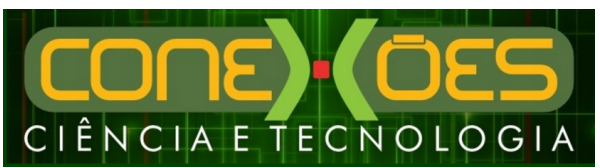

PANORAMA DA ACESSIBILIDADE NOS HOTÉIS 5 ESTRELAS DE FORTALEZA - CEARÁ

\title{
PANORAMA DA ACESSIBILIDADE NOS HOTÉIS 5 ESTRELAS DE FORTALEZA - CEARÁ
}

\author{
Júlio César Ferreira Lima ${ }^{1}$, Marcelo Bastos Pereira Filho ${ }^{1}$ \\ ${ }^{1}$ Instituto Federal do Ceará (IFCE) \\ $<$ julioepedrita@gmail.com><marcelo.bastos@casablancaturismo.com.br>
}

DOI: 10.21439/conexoes.v12i3.1269

\begin{abstract}
Resumo. A sociedade contemporânea discute e defende a igualdade de todos os indivíduos. Compondo parte dessa sociedade, encontram-se as pessoas com mobilidade reduzida (PMR). Os diversos setores sociais, pois, devem estar preparados para acolher esses cidadãos por meio de uma acessibilidade de qualidade. A hotelaria, como importante área econômica, também deve estar ciente da importância em recepcionar bem as PMR em seus empreendimentos. O objetivo geral desse estudo é explorar as condições de acessibilidade para PMR nos hotéis de categoria 5 estrelas de Fortaleza. Os objetivos específicos buscaram identificar as necessidades básicas das PMR dentro de meios de hospedagem, segundo as normativas de acessibilidade da ABNT e do manual implantado pela EMBRATUR, e assinalar as condições de acessibilidade de cada hotel pesquisado. $\mathrm{O}$ trabalho se caracteriza como um estudo de caso exploratório, através do método indutivo, com abordagem de caráter qualitativo. Foram realizadas pesquisas bibliográficas e uma pesquisa de campo, apresentando 1 questionário como o instrumento fornecedor dos dados, respondido pelos responsáveis dos departamentos de hospedagem dos hotéis. A análise dos resultados mostrou que nenhum dos hotéis visitados apresentava todos os itens necessários para acessibilidade conforme regem as leis e também que não estavam de acordo com as exigências estabelecidas pelas normas em números de apartamentos acessíveis. Concluiu-se, então, que os hotéis 5 estrelas de Fortaleza não apresentavam uma ampla acessibilidade para recepcionar hóspedes com mobilidade reduzida.
\end{abstract}

Palavras-chaves: Acessibilidade. Hotelaria. Inclusão Social. Pessoas com Mobilidade Reduzida.

\section{A PANORAMA OF ACCESSIBILITY AT FIVE-STAR HOTELS IN FORTALEZA - CEARÁ}

\begin{abstract}
Contemporary society discusses and defends the equality of all individuals. Part of this society comprises people with reduced mobility (PRM). Therefore, the various social sectors must be prepared to welcome these citizens through proper accessibility. The hotel industry, as an important economic area, should also be aware of the importance of well receiving PRMs. The general objective of this study is to exploree the accessibility conditions for PRM in Fortaleza's 5-star hotels. The specific objectives sought to identify the basic needs of the PRMs within the lodging facilities, according to the ABNT accessibility norms and the manual implemented by EMBRATUR; and to determine the accessibility conditions of each hotel searched. The work is characterized as an exploratory case study, through the inductive method, with a qualitative approach. A bibliographical research and a field research were carried out, presenting a questionnaire as the instrument for providing the data, answered by the workers in charge of the lodging departments of the hotels. The analysis of the results showed that none of the hotels visited had all the necessary items for accessibility according to the laws, and also that they did not follow the requirements established by the norms in accessible apartment numbers. It was concluded that the 5- star hotels in Fortaleza did not present an ample accessibility to receive guests with reduced mobility.
\end{abstract}

Keywords: Accessibility. Hospitality. Social Inclusion. People with Reduced Mobility. 


\section{INTRODUÇÃO}

Entre os objetivos de melhoria social debatidos atualmente está a sensibilização da sociedade para o direito de ir e vir das pessoas com mobilidade reduzida (PMR). Portanto, presenciam-se surgir transformações relevantes em um movimento abrangente de inclusão social. Esse movimento é decorrente de uma melhor percepção social e de um universo democrático, em que se almeja respeitar os direitos e os deveres dos cidadãos. De acordo com Lima (2012, p. 20):

\begin{abstract}
A aproximação da igualdade entre os indivíduos dentro de uma mesma sociedade acontece principalmente através da inclusão social. Essa inclusão acontece como fator dicotômico para as mais variadas formas de exclusão como educacional, econômica, política, religiosa, digital, etc. Para se obter mais êxito com a inclusão, é preciso uma compreensão da igualdade de todos como um padrão cultural a ser seguido por toda a sociedade. Essa igualdade é na verdade o direito de todos os indivíduos de possuírem acesso aos mesmos instrumentos sociais, civis e políticos para que a partir desse momento as diferenças possam existir. As diferenças surgirão, então, não da exclusão de uns, mas do desejo e/ou competência de outros para ir mais além do que lhes é exposto.
\end{abstract}

As barreiras limitadoras do indivíduo não abrandam seus direitos. Todos são cidadãos e fazem parte da mesma sociedade. Há, contudo, a necessidade de uma organização social para lidar com as desigualdades humanas. Dos diversos fatores deparados, um dos que se destaca é o problema da acessibilidade, que mostra um dilatado espaço para melhorias. De acordo com o Art. $8^{\circ}$ do Decreto 5296, de 02 de dezembro de 2004, acessibilidade é a

Condição para utilização, com segurança e autonomia, total ou assistida, dos espaços, mobiliários e equipamentos urbanos, das edificações, dos serviços de transporte e dos dispositivos, sistemas e meios de comunicação e informação, por pessoa portadora de deficiência ou com mobilidade reduzida.

A Associação Brasileira de Normas Técnicas (ABNT) é responsável em instituir e publicar normas brasileiras desde a década de 40. Logo, compete a essa entidade criar as regras de acessibilidade para facilitar e assegurar livre acesso aos indivíduos com mobilidade reduzida. Em novembro de 2015, foi elaborada a última revisão na NBR 9050, que é a normativa referente à acessibilidade.

Segundo o conceito da ABNT, as PMR possuem limitada capacidade de se relacionar com o meio e de utilizá-lo. Essa limitação pode ser permanente ou temporária. Entende-se por PMR o indivíduo com algum tipo de deficiência, idade avançada, obesidade ou gravidez, entre outras características (ABNT NBR
9050/2015). Nem sempre essas pessoas se enquadram no conceito de pessoas portadoras de deficiências, contudo, por outros motivos, as PMR possuem dificuldades de locomoção, acarretando em uma efetiva redução da mobilidade, flexibilidade, coordenação motora e percepção. Sendo assim, as normas de acessibilidades para pessoas com mobilidade reduzidas têm igual valor às normativas dos deficientes.

Conforme Silva (2004), inúmeras PMR não têm assegurado o direito de ir e vir. As PMR se inserem na sociedade de forma precária por não se beneficiar dos bens e espaços coletivos de maneira satisfatória, uma vez que esses foram planejados e executados para os ditos "normais." Em hotéis, esta prática não é diferente, pois esses ambientes também são resultados de uma sociedade pensada sob a perspectiva do homem sem deficiência.

Nesse estudo, foi abordado o atendimento às pessoas com mobilidade reduzida em um tipo de empreendimento hoteleiro da cidade de Fortaleza. Para essa exposição, as seguintes questões de pesquisas foram levantadas: Os hotéis de categoria cinco estrelas de Fortaleza estão preparados para recepcionar as PMR? As instalações desses hotéis oferecem adequadas estruturas, atendimento e conforto para atender às expectativas desse perfil de hóspedes?

Desse modo, o objetivo geral do trabalho se constituiu em explorar as condições de acessibilidade para PMR nos três hotéis de categoria 5 estrelas de Fortaleza, em observância às normas de acessibilidade. Essa análise aconteceu através de dois objetivos específicos, a saber, identificar as necessidades básicas desses indivíduos dentro dos meios de hospedagem por meio das normas mais atualizadas e difundidas no Brasil e assinalar as condições acessíveis de cada hotel visitado.

Essa pesquisa é justificada pelo notório e crescente aumento da consciência coletiva sobre inclusão social nas mais variadas esferas sociais. No Brasil, devido à situação atual de violência urbana, principalmente acidentes com arma de fogo e no trânsito, a estimativa é que cerca de 8.000 pessoas entram para o grupo de PMR todos os meses 11 Dessa forma, pode-se inferir que quanto maior for o grau de problemas urbanos em um país, mais elevada será a quantia de cidadãos com mobilidade reduzida.

Para adequar-se a essa realidade, os meios de hospedagem também devem estar alinhados e engajados na receptividade dos diversos tipos de pessoas, atendendo a suas diversas necessidades. Pessoas com mobilidade reduzidas também possuem direito para usufruir dos

${ }^{1}$ Os dados apresentados foram encontrados na matéria "Dados da Deficiência" encontrada no site I.social: soluções em inclusão social. 
equipamentos do trade turístico.

O Instituto Brasileiro de Turismo (EMBRATUR) criou o Manual de Recepção e Acessibilidade de Portadores de Deficiência a Empreendimentos e Equipamentos Turísticos. O propósito maior desta publicação foi garantir igualdade de acesso dentro da hotelaria e áreas de entretenimento presentes nas cidades brasileiras (EMBRATUR, 1999).

Com a criação de normas de acessibilidade, ocorreu uma possibilidade da participação de PMR em diversas atividades, antes praticadas apenas por pessoas sem nenhum tipo de deficiência, tais como: atividades esportivas, eventos e atividades turísticas. Com esse maior entendimento legal, verificou-se a necessidade de adaptação de ambientes para esses deficientes, surgindo assim, o trabalho de modificação também em meios de hospedagem para recepcionar mais adequadamente esses hóspedes.

Em julho de 2015, foi sancionada em Brasília a lei que atualizou o Estatuto da Pessoa com Deficiência. O texto completo dividiu opiniões, como no parágrafo $1^{\circ}$ do Art. 45 qudiscorria sobre a disponibilidade de $10 \%$ dos apartamentos acessíveis de toda a cadeia hoteleira no Brasil, ainda que observados o prazo de 24 meses para adequação dos estabelecimentos. Antes, a porcentagem destinada a este público era de $5 \%$ apenas (ESTATUTO DA PESSOA COM DEFICIÊNCIA, 2015).

Segundo Castelli (2003, p. 56), “uma organização hoteleira pode ser entendida como sendo uma empresa que, mediante o pagamento de diárias, oferece alojamento à clientela indiscriminada". Dessa mesma forma, Goulart (2007) defende que os gastos para adaptar um hotel, deveriam ser vistos como melhoria não só para PMR, mas também para outros grupos de cidadãos. Pode ser frustrante para uma pessoa com limitações de mobilidade, quando o acesso às áreas comuns do hotel é difícil ou impossibilidade. Nesse contexto, entende-se que a partir do momento em que uma PMR contrata o produto do hotel, ele tem o mesmo direto de satisfação quanto uma pessoa sem necessidades especiais.

Conforme o Ministério do Turismo (2013), 14 projetos estão sendo financiados pelo governo federal, envolvendo acessibilidade no turismo, em uma tentativa de incluir nas atividades turísticas cerca de 45 milhões de brasileiros portadores de algum tipo de deficiência. O setor hoteleiro também está fortemente inserido nesses investimentos. Na hotelaria, a adequação dessas novas normas baseia-se pelo Manual já citado anteriormente.

\section{METODOLOGIA}

No presente estudo, o método de abordagem indutivo foi utilizado para a análise das estruturas dos apartamentos com acessibilidade para PMR de 3 (três) hotéis 5 (cinco) estrelas da cidade de Fortaleza. A partir de então se poderia chegar a uma conclusão genérica a respeito dos investimentos para a melhoria da acessibilidade em empreendimentos representativos do turismo.

Do ponto de vista dos objetivos, tratou-se de um estudo de caso por meio de uma pesquisa exploratória, em que se faz necessário proporcionar uma maior familiaridade com a problemática abordada. Aqui a pesquisa buscou o conhecimento quanto à estrutura de quartos adaptados em hotéis de alto padrão, podendo servir como diferencial de serviços oferecidos no ramo da hotelaria e adequação às necessidades da sociedade contemporânea.

Para os procedimentos técnicos, utilizou-se pesquisa do tipo documental, bibliográfica e pesquisa de campo. A pesquisa documental baseou-se nos regulamentos e normas do Manual de Recepção e Acessibilidade de Portadores de Deficiência a Empreendimentos e Equipamentos Turísticos, implantado pela EMBRATUR. Consultou-se também as regras da ABNT - NBR 9050/2015.

As principais fontes bibliográficas utilizadas foram obras de Gabrilli (2012), Carletto; Cambiaghi (2008), Sassaki (2005) e Castelli (2003), entre outros. A literatura produzida pelos referidos autores serviu como base teórica para os temas de administração hoteleira, acessibilidade na hotelaria, de inclusão de pessoas portadoras de deficiências na sociedade, do Desenho Universal e outras temáticas abordadas.

A pesquisa de campo foi realizada no mês de dezembro de 2014, quando se visitou os três hotéis de categoria 5 estrelas encontrados na cidade de Fortaleza, citados no trabalho como Hotel A, Hotel B e Hotel C. Os dados necessários para a realização da pesquisa foram captados por meio da aplicação de um questionário com 16 perguntas objetivas e respondido pelo responsável do departamento de hospedagem de cada hotel. As perguntas versavam sobre os itens básicos de acessibilidade em cada estabelecimento. O questionário possuía perguntas dicotômicas, algumas com espaços para comentários e outras com possibilidades de múltiplas escolhas quando a resposta inicial fosse afirmativa.

\section{RETRATO DA DEFICIÊNCIA NO BRASIL: UMA FATIA DO GRUPO DE PMR}

A expressão "pessoas com mobilidade reduzida" é associado geralmente somente à deficiência física. $\mathrm{Na}$ 
verdade, esse grupo é também composto por outros cidadãos. Para se incluir nesse grupo, uma pessoa precisa estar apenas com alguma função motora ou intelectual comprometida temporária ou permanentemente no que diz respeito ao pleno funcionamento.

Mesmo assim, grande parcela de PMR realmente apresenta alguma deficiência física. Pita (2011) publicou no site Terra $2^{2}$ que na última análise do Censo de 2010 foi constatado o crescimento de dez pontos percentuais no número de pessoas com deficiência, em relação ao Censo do ano 2000. A cifra indica que cerca de um quarto da população brasileira pertence a esse grupo. Essa progressão pode estar associada ao estilo de vida da sociedade atual: violência urbana exacerbada, novas patologias, epidemias, etc. Com esse aumento tendencioso, mais ações inclusivas devem ser criadas objetivando maior participação de cidadãos nas mais variadas atividades sociais.

A inclusão social é um ponto instigante e desafiador em qualquer sociedade contemporânea. O termo inclusão aparece, na verdade, compondo uma dualidade com o termo exclusão para caracterizar um mesmo fator social, por isso são normalmente mencionados juntos. As desigualdades de tratamento nas mais variadas regiões do planeta são agravantes para o bom funcionamento social, político e civil dos cidadãos. O Brasil não se encontra entre os países mais responsáveis no cumprimento de direitos dos cidadãos. Na realidade, de acordo com Lima:

\begin{abstract}
O Brasil tem a inclusão social como um dos grandes desafios, desde o início de sua história. Brasileiro é o povo marcado inicialmente pelo conceito discriminador entre colonizador e colonizado, uma vez que ser trazido para o Brasil era para muitos portugueses um castigo de degradação, por não poder mais se morar na corte. Reúne-se a esse fato, o período vergonhoso de escravidão implantado no país, quando negros e índios foram humilhados no mais alto nível, por terem sua liberdade tomada abruptamente e a partir de então passarem a simbolizar "objetos" de demonstração de riqueza dos seus "senhores". Diante disso, o Brasil acumulou um vasto conjunto de desigualdades sociais, no que concerne à distribuição de riquezas, de terras, de acesso aos bens materiais e culturais e, chegando à atualidade, à apropriação dos conhecimentos científicos e tecnológicos. Lima (2012, p. 66)
\end{abstract}

Conforme o conceito da Organização das Nações Unidas (ONU), "pessoas com deficiência são aquelas que têm impedimentos de longo prazo de natureza física, mental, intelectual ou sensorial" (CONVENÇÃO SOBRE OS DIREITOS DAS PESSOAS COM DEFICIÊNCIAS, 2008, p. 26). Essas deficiências, em interação às inúmeras barreiras, bloqueiam a participa-

\footnotetext{
${ }^{2}$ Os dados apresentados foram encontrados na matéria "Deficientes representam $24 \%$ da população do Brasil, diz IBGE".
}

ção plena e efetiva dessas pessoas na sociedade, ocasionando, assim, um tipo de exclusão social.

Há várias formas de exclusão a deficientes, como na educação, no transporte público, nas atividades profissionais, em atendimentos não especializados, etc. Lima (2012) defende que a questão do binômio exclusão/inclusão é realmente muito mais abrangente. Para o autor:

\footnotetext{
Inclusão social é um termo normalmente associado à inserção de pessoas com deficiência física ou mental às escolas de ensino regular e ao mercado de trabalho. Todavia a amplitude do termo abrange contextos diferentes, em referência a questões sociais variadas [...]. Outro ponto a ser considerado é que os termos, inclusão e exclusão, têm que ser dissociados de riqueza e pobreza, respectivamente. Ligados à inclusão, e consequentemente à exclusão, temos elementos éticos e culturais relacionados à discriminação e à estigmatização. (LIMA, 2012, p. 65,66)
}

Entre as ideias para sanar esse problema social, Sassaki (2004) afirma que é preciso mudar o conceito sobre acessibilidade. Para o autor, a sociedade precisa substituir o "paradigma da integração social" pelo "paradigma da inclusão social." Na visão de Sassaki (2005. p. 20), "a inclusão é um processo mundial irreversível, pois é a partir de práticas baseadas na valorização da diversidade humana, no respeito pelas diferenças individuais que se abrem caminhos para a construção de uma sociedade verdadeiramente para todos". Essa substituição consiste em tornar o ambiente social viável a todos os tipos de cidadãos, com necessidades especiais ou não, visto que a ideia do paradigma atual preocupa-se apenas em elaborar sistemas sociais comuns adaptáveis, cabendo a essas pessoas incluir-se ou não.

Nessa mesma linha de raciocínio, Garcia (2008) defende que a proposta desse novo conceito de inclusão social é criar espaços onde pessoas com e sem deficiências possam usufruí-los com igualdade. Esse novo conceito critica as construções de ambientes para uso exclusivo de deficientes, considerando que esta forma é também discriminatória. Com isso, pode-se entender então que na hotelaria não se deve restringir a acessibilidade apenas promovendo adaptações de algumas unidades habitacionais (UH). O correto seria adequar todos os apartamentos e áreas comuns do hotel para que qualquer pessoa pudesse usufruir dos mesmos espaços com uniformidade e dignidade.

Medidas e ações prudentes devem ser adotadas para que adversidades de inclusão ligadas às PMR sejam sanadas em todos os setores sociais, inclusive na hotelaria. Os hotéis devem estar equipados e estruturados de acordo como regem as leis de acessibilidade. As PMR não devem estar integradas na sociedade, e sim inclu- 
sas, pois é apenas a inclusão que traz a valorização real das pessoas.

\section{HOTEIS ADAPTADOS}

A noção de hospitalidade é uma constante que atravessa a história da humanidade e apresenta nuances de acordo com cada cultura. Inclusive, o termo chega a fundamentar o conceito de turismo e a compor uma área de estudo, a saber, o Turismo e a Hospitalidade. Apresentando traços diferentes, mas com algumas semelhanças, a hospitalidade é exemplificada entre os gregos, entre os beduínos do deserto, entre os monges e outros religiosos, e até mesmos entre os índios, que já há muito tempo demonstram grande respeito pelos viajantes.

Para González (2002, p. 92), a hospitalidade "sempre manda receber bem o forasteiro, o visitante, e fazêlo sentir-se como na própria casa, ou ainda melhor." Corroborando com essa ideia, no conceito de Lashley (2004), o termo hospitalidade é, então, relacionamento. $\mathrm{O}$ autor considera que as relações de hospitalidade entre hospedeiro e o hóspede não se resumem apenas às prestações de serviços de abrigo e alimentação. A partir do momento em que o anfitrião decide receber um hóspede, ele passa a assumir o dever de deixá-lo satisfeito. Mesmo com a modernização, González (2002, p. 94) assegura que "a urbanização crescente, a tecnologia e o turismo de massas deram outras matizes à hospitalidade. Conserva-se, porém, a cordialidade na acolhida ao visitante".

Levando esse conceito para a hotelaria, Lashley (2004, p.4) entende que quando um hotel resolve "hospedar uma pessoa com mobilidade reduzida, além dos itens básicos de hospedagem, o hoteleiro tem o dever de proporcionar bem estar a esse hóspede, oferecendo adequadas condições e estruturas físicas para que possa garantir a comodidade do mesmo." Esse conceito vem de encontro ao que dizia González (2002), quando afirmava que a profissionalização do turismo no momento atual trazia outras exigências além da boa vontade e do coração aberto.

A necessidade de adequação na área do Turismo e Hospitalidade deixa de ser centralizada, pois, apenas em seus profissionais e passa a focar também o público alvo. Na visão de Goulart (2007), a maioria das adaptações implementadas em empreendimentos hoteleiros para atender PMR está ainda em número muito reduzido ao sugerido pelos manuais especializados sobre o gênero, não abrangendo a maioria do público alvo. Dentre essas adaptações atualmente praticadas estão o alargamento de portas e a instalações de barras próximas a aparelhos sanitários. Segundo matéria publicada pela Revista Hotéis (2011), o Brasil possuía naquele ano mais de 9.000 hotéis, porém muitos desses empreendimentos ainda não haviam se conscientizado da importância da adequação dos seus empreendimentos para atender PMR.

Como asseveram Cardoso e Strassburges (2012), na tentativa de atender às legislações, a maioria dos estabelecimentos de hospedagem reserva um baixo número de apartamentos para PMR, colocando algumas barras de apoio no banheiro, acreditando ter tornado o quarto acessível. Todavia, é sabido que outras condições são necessárias para adaptar um meio de hospedagem adequadamente. Ainda para Cardoso e Strassburges (2012, p. 14), "a hotelaria deve-se lembrar, e seguir, das demais exigências normativas das edificações, como por exemplo, rampas para acesso de pessoas usuárias de cadeira de rodas, elevadores mais largos, balcões de atendimento rebaixados, entre outras." Essas ações não podem ser tomadas de maneiras aleatórias, pois há normativas e regras de acessibilidade a serem seguidas e fiscalizadas. Medidas improvisadas não trazem a verdadeira função da acessibilidade, que é a de inclusão das PMR nos ambientes comuns a todos.

\section{O DESENHO UNIVERSAL}

A ideia de criar produtos, meios de comunicação e ambientes que possam ser utilizados por qualquer cidadão, independente de idade, estatura ou capacidade, sem a necessidade de adaptação ou auxilio é o conceito do Desenho Universal (DU) (CARLETTO; CAMBIAGHI, 2008). O DU busca a inclusão de todas as pessoas nos distintos segmentos sociais, propondo bemestar e conforto, sejam elas pessoas com mobilidade reduzida, pessoas com e sem deficiência.

A ABNT já determinava em sua normativa de acessibilidade que todos os projetos arquitetônicos do país seguissem os princípios do DU. No ano de 2015, contudo, esses princípios foram expostos de uma forma mais ampla, trazendo um design mais inclusivo, "centrados no ser humano e na sua diversidade"(NBR 9050/2015, p.139).

A concepção de conforto está ligada a diversos fatores pessoais, como altura, dimensão, idade, força, destreza e outras características. Todavia, com a diversidade de pessoas existentes no planeta, fica difícil, ou mesmo impossível, padronizar todos os seres humanos dentro de uma única categoria abrangendo suas características físicas e mentais. Mesmo assim, desde meados do século XX, esforços estão sendo realizados em busca de equipamentos mais igualitários para todos os cidadãos, como visto a seguir:

Em 1961, alguns países como Japão, EUA, e Nações Europeias, iniciaram um debate sobre a reestruturação 


\begin{abstract}
do conceito para o dito "homem padrão", pois este nem sempre é o "homem real". Devem ser lembradas e valorizadas as diversidades físicas e mentais dos seres humanos. [...]. Esta primeira conferência internacional, realizada na Suécia, foi berço para a criação de uma comissão, em 1963, que criaria desenhos de equipamentos, edifícios e área urbana adequados para pessoas com deficiência físicas ou mobilidade reduzida. Essa comissão foi chamada de Barrier Free Designer. Com o passar dos anos, após muitos discursos e amadurecimento de ideias, esse conceito ampliou seu foco, mudou de nome e passou a ser chamado de Desenho Universal, Universal Designer, propondo atender a todas as pessoas, em um aspecto realmente universal. (CARLETTO; CAMBIAGHI, 2008, p. 11)
\end{abstract}

Segundo Carletto e Cambiaghi (2008), um debate sobre o DU, começou em 1980 no Brasil, com a intenção de conscientizar profissionais da área da construção civil. Em seguida, as Nações Unidas declararam o ano de 1981 como o Ano Internacional das Pessoas Deficientes. Discussões em nível mundial acabaram repercutindo no Brasil e favoreceram fortemente o assunto sobre os direitos de PMR. Por conta dos debates, foram criadas algumas leis que garantissem a acessibilidade de PMR a vias urbanas (como ruas e praças) e a prédios públicos e privados (como em hotéis), visto que esses cidadãos também pagam impostos e devem ser incluídos nos planos de organização e mobilidade urbana.

O projeto do DU almeja uma abrangência universal, pois seu conceito visa atingir o maior número possível de pessoas. Seguindo esse pensamento de produtos sem distinção de público, encontra-se o posicionamento de Carletto e Cambiaghi quando afirmam que:

\begin{abstract}
Os produtos universais acomodam uma escala larga de preferências e de habilidades individuais ou sensoriais dos usuários. Qualquer ambiente ou produto deverá ser alcançado, manipulado e usado. Independentemente do tamanho do corpo do indivíduo, sua postura ou sua mobilidade. Dessa forma entende-se que o Desenho Universal não é uma tecnologia direcionada apenas aos que dele necessitam, mas é desenhado para todos os indivíduos, apresentem eles algum prejuízo de mobilidade ou não. A sua ideia é evitar a necessidade de ambientes e produtos especiais, assegurando que todos possam utilizar com segurança e autonomia os diversos objetos e espaços construídos. (CARLETTO; CAMBIAGHI, 2008, p.8)
\end{abstract}

Equiparada à ideia de Sassaki (2005), quando defendeu o paradigma da inclusão social, a proposta do DU também tem um forte parâmetro de inclusão social. A partir desse princípio, um ambiente totalmente equipado e confortável para todos os tipos de indivíduos, sem restrições, traz claramente o ideal da inclusão, pois dessa forma, todas as pessoas poderão usufruir igualitariamente dos espaços em comum.
Na década de 1990, foram criados os setes princípios básicos do Desenho Universal, a fim de alcançar os propósitos de maneira mais sistematizada. O inter-relacionamento dos princípios objetiva primordialmente acomodar pessoas de diversos padrões. O DU deve apresentar as sete características do quadro a seguir:

Voltando-se para a área da Hotelaria, Bossini (2010) declara que ao se projetar um hotel, deve-se considerar a rotatividade de pessoas, suas diferenças socioeconômicas e culturais. Cada cliente tem sua individualidade, restrições e habilidades e essas diferenças devem ser respeitadas. Pôr portas mais largas nos apartamentos, maçanetas rebaixadas, espaços nos ambientes para manobras e barras de apoio nos banheiros são exemplos de medidas defendidas pelo Desenho Universal que respeitariam as particularidades de um hóspede com mobilidade reduzida, sem intervir nas tarefas dos hóspedes sem deficiências.

\section{RESULTADOS E DISCUSSÕES}

De acordo com as informações obtidas através da aplicação do questionário em cada um dos hotéis visitados, pode-se constatar o cumprimento de algumas normas de acessibilidade e a ausência ou desconhecimento de outros itens básicos exigidos pelas normas. Alguns aspectos negativos e positivos coincidiram nos hotéis avaliados.

Sobre os pontos negativos em comum, pode-se identificar que nenhum dos empreendimentos possuía a quantidade mínima de unidades acessíveis para PMR (Quadro 2). A ABNT NBR 9050/2015 estabelece que o mínimo de $5 \%$ do número total de apartamentos de um hotel deve apresentar adaptações para o referido público, sendo ainda recomendados $10 \%$ pelo Estatuto da Pessoa com Deficiência.

Como pode ser observada, a cifra de unidades apropriadas para PMR está distante do ideal. Mesmo para hotéis enquadrados em uma categoria de padrão alto, como os pesquisados, ainda não há uma estruturação adequada para esse segmento de mercado que exige atenção especial no que diz respeito à acessibilidade em qualquer tipo de estabelecimento público ou privado.

Nenhum dos hotéis apresentou estrutura com balcão de atendimento rebaixado ou automático, para operacionalização dos procedimentos de check-in (entrada) e check-out (saída) às PMR, conforme sugerido pelo Manual da Embratur. Também não foi constatada a presença de esteiras rolantes para facilitar o acesso às diversas áreas do hotel. A ausência desses equipamentos mais "específicos" demonstra que hóspedes com mobilidade reduzida ainda enfrentam indiferença no que diz 


\begin{tabular}{|l|l|l|}
\hline \multicolumn{1}{|c|}{ PRINCÍPIOS } & \multicolumn{1}{|c|}{ EXPLICAÇÃO } & \multicolumn{1}{|c|}{ EXEMPLO } \\
\hline Igualitário & $\begin{array}{l}\text { Espaços, objetos e produtos que podem ser } \\
\text { utilizados por pessoas com diferentes } \\
\text { capacidades. }\end{array}$ & $\begin{array}{l}\text { Portas com sensores que se abrem } \\
\text { sem exigir força física. }\end{array}$ \\
\hline Adaptável & $\begin{array}{l}\text { Design de produtos ou espaços que atendam } \\
\text { pessoas com diferentes habilidades e es } \\
\text { preferências, sendo adaptáveis a qualquer uso. }\end{array}$ & $\begin{array}{l}\text { Tesoura que serve a destros e } \\
\text { canhotos. }\end{array}$ \\
\hline Obvio & $\begin{array}{l}\text { De fácil compreensão, independentemente da } \\
\text { experiência, conhecimento, habilidades de de } \\
\text { linguagem, ou nivel de concentração pessoal. }\end{array}$ & $\begin{array}{l}\text { Placa indicativa com figuras de } \\
\text { sanitário masculino e para pessoas } \\
\text { com deficiência. }\end{array}$ \\
\hline Conhecido & $\begin{array}{l}\text { Informação transmitida de forma a atender as } \\
\text { necessidades do receptador, seja ela uma } \\
\text { pessoa estrangeira, com dificuldade de visão ou } \\
\text { audição. }\end{array}$ & $\begin{array}{l}\text { Utilização de diversas maneiras de } \\
\text { comunicação, tais como símbolos e } \\
\text { letras em relevo, braille e } \\
\text { sinalização auditiva. }\end{array}$ \\
\hline Seguro & $\begin{array}{l}\text { Previsto para minimizar os riscos e possíveis } \\
\text { consequências de ações acidentais ou não } \\
\text { intencionais. }\end{array}$ & $\begin{array}{l}\text { Elevadores com sensores em } \\
\text { diversas alturas permitindo a } \\
\text { entrada sem riscos de fechamento } \\
\text { no meio do processo. }\end{array}$ \\
\hline Sem esforço & $\begin{array}{l}\text { Utilização eficiente, com conforto e com o } \\
\text { mínimo de fadiga. }\end{array}$ & $\begin{array}{l}\text { Torneiras com sensores ou } \\
\text { alavanca. }\end{array}$ \\
\hline Abrangente & $\begin{array}{l}\text { Dimensões e espaços apropriados para o } \\
\text { acesso, o alcance, a manipulação e o uso, } \\
\text { independentemente do tamanho do corpo, da } \\
\text { postura ou mobilidade do usuário. }\end{array}$ & $\begin{array}{l}\text { Banheiros com dimensões para } \\
\text { cadeirantes e pessoas com bebês } \\
\text { em carrinhos. }\end{array}$ \\
\hline
\end{tabular}

Fonte: Adaptado de Carletto e Cambiaghi (2008)

Quadro 2: Unidades acessíveis dos hotéis pesquisados

\begin{tabular}{|c|c|c|c|c|}
\hline Hotel & $\begin{array}{c}\mathbf{N}^{\circ} \text { de unidades } \\
\text { total }\end{array}$ & $\begin{array}{c}\mathbf{N}^{\circ} \text { de unidades acessíveis } \\
\text { estabelecidas pela ABNT }\end{array}$ & $\begin{array}{c}\mathbf{N}^{\circ} \text { de unidades } \\
\text { acessíveis }\end{array}$ & $\begin{array}{c}\text { Percentual de } \\
\text { unidades acessíveis }\end{array}$ \\
\hline Hotel A & 320 & 16 & 2 & $0,62 \%$ \\
\hline Hotel B & 217 & 11 & 4 & $1,84 \%$ \\
\hline Hotel C & 230 & 12 & 3 & $1,30 \%$ \\
\hline
\end{tabular}

Fonte: Dados da pesquisa (2014)

respeito a seus direitos como cidadãos plenos.

Apesar dos gerentes de hospedagem ter algumas noções sobre infraestrutura acessível, os mesmos não tinham conhecimentos a respeito das leis impostas pelas normativas da ABNT NBR 9050/2015, por isso não souberam informar se as medidas métricas indagadas no questionário estavam de acordo com as estabelecidas por lei. A falta de conhecimento às normas técnicas da ABNT pelos responsáveis pela administração dos estabelecimentos demonstra que nesses hotéis não há uma real preocupação ao atendimento de PMR. Do contrário, os gestores seriam conscientes das normas que regem a acessibilidade no Brasil.

Dentre os aspectos positivos comuns aos hotéis avaliados, identificou-se a existência dos principais itens de acessibilidade nas áreas comuns. Foi declarado pelos 3 gestores que os empreendimentos possuíam ram- pas, corrimãos e revestimentos resistentes, criados para resistir a impactos provocados por bengalas, muletas e cadeiras de rodas. Observou-se ainda que os banheiros possuíam barras sanitárias, bancos no interior do box nos banheiros e lavatórios suspensos sem coluna ou gabinete de sustentação. Todos os quartos acessíveis possuíam espaços amplos para a circulação de uma cadeira de rodas, caso necessário. Quanto aos estacionamentos, todos possuíam vagas específicas para PMR.

A presença dos equipamentos, citados no parágrafo acima, mostra que, em geral, os empreendimentos estão alinhados às exigências das normas mais básicas de acessibilidade. Numa avalição menos criteriosa, pode-se até enquadrar os respectivos hotéis em modelo de "hotéis acessíveis". Porém, é sabido que apenas a implantação de alguns itens básicos de acessibilidade não é suficiente para tornar estabelecimentos hoteleiros 
acessíveis e inclusivos. Necessita-se, na verdade, que as dependências dos hotéis estejam com os espaços e equipamentos adequados para serem aproveitados por todas as pessoas, independente de suas características físicas ou habilidades. Essa adequação satisfaz assim o objetivo primeiro do DU que é projetar ambientes, produtos e equipamentos voltados à diversidade humana, para utilização de forma igualitária e independente.

Mesmo a pesquisa tendo sido realizada em hotéis de uma mesma categoria hoteleira, verificou-se que os empreendimentos são diferenciados pela presença variada de outros itens adequados à acessibilidade (Quadro 3). Se considerados os itens de acessibilidade não apresentados por nenhum dos hotéis, como também a variação do quadro a seguir, nota-se que ainda há muito a ser realizado para se atingir o que é proposto pelo DU, objetivando atender a maior parcela da população possível.

O Hotel A é um empreendimento antigo e de bandeira independente ${ }^{3}$. Em 2014, ele passou por algumas reformas nos apartamentos, inclusive nas unidades com acessibilidade. Atualmente, esses apartamentos possuem janelas com altura acessível ao alcance visual de pessoas em cadeiras de rodas e possuem controles, comandos e puxadores dentro da altura necessária para cadeirantes, que é de 1,20m a partir do piso. Em contrapartida, nota-se a ausência de escadas rolantes em áreas comuns. Os elevadores são visivelmente estreitos, não atendendo a regra de $110 \mathrm{~cm}$ de largura e não possuem corrimão na parte interna da cabine, tornandose fora do padrão exigido pela ABNT. Os armários dos apartamentos não apresentam a parte inferior instalada a $0,30 \mathrm{~m}$ do piso, conforme rege a normativa. Tão pouco foi detectada a presença de sinalização feita através dos símbolos internacionais de acesso, indicando que o ambiente possuía acessibilidade para pessoas com deficiência ou com mobilidade reduzida.

O Hotel B pertence a uma rede de hotéis. Sobre os itens de acessibilidade diferenciados, destaca-se a presença de escadas rolantes, que dão acesso à área de eventos do hotel. O hotel também possui elevadores apropriados com espaços para cadeirantes e barras de corrimão em sua área interna. Os armários apresentam a parte inferior instalada a $0,30 \mathrm{~m}$ do piso, deixando espaço abaixo livre para qualquer saliência ou obstáculo. Dentre os aspectos negativos, estão as janelas que, mesmo pertencentes a apartamentos acessíveis, não possuem altura adequada ao alcance de pessoas em cadeiras de rodas. Há também a ausência de controles, comandos e puxadores dentro da altura necessária para

\footnotetext{
${ }^{3}$ Hotel de bandeira independente possui administração própria Esse modelo administrativo de hotel não está ligado, pois, às normas e padrões exigidos por redes hoteleiras (Nota dos autores).
}

cadeirantes. Como no Hotel A, não foi localizada no Hotel B a sinalização feita através dos símbolos internacionais de acesso.

O Hotel C é um hotel de bandeira independente com grande destaque na cidade de Fortaleza por seu requinte e luxo. Em suas áreas comuns, os elevadores são amplos, com sinais sonoros e barras de corrimão na área interna. Os quartos acessíveis possuem janelas de acordo com altura exigida pela norma. Encontramse dentro desses apartamentos controles, comandos e puxadores dentro da altura necessária para cadeirantes; além de armários instalados adequadamente, com parte inferior a $0,30 \mathrm{~m}$ do piso. O hotel proporciona saídas de emergência para os hóspedes que possuem problemas para se locomover, não dificultando seu acesso através de locais rebaixados ou elevados. O Hotel $\mathrm{C}$ possui áreas fitness e piscina com fácil acesso às PMR. No estacionamento, além das vagas para deficientes, o hotel possui manobristas, que facilitam a entrada e saída do hospede no hotel. Como ponto negativo, registra-se a presença do símbolo internacional de acesso apenas nos quartos acessíveis, sem outras indicações nas áreas comuns. O hotel tão pouco possui escadas rolantes, mas, segundo o gerente, há intenção em instalar o equipamento. O processo de instalação é somente um plano, ainda sem previsão de execução.

De acordo com o avaliado, consta-se que dos 3 hotéis apenas o Hotel $\mathrm{C}$ possui todos os itens de acessibilidade em suas unidades acessíveis. Contudo, ainda há importantes transformações a serem feitas nas áreas comuns aos hóspedes. Os outros 2 hotéis pesquisados mostraram-se ainda distantes do ideal expresso pelas normativas às PMR. Os resultados obtidos revelam que a hotelaria 5 estrelas de Fortaleza ainda não está adequada ao padrão idealizado pelos defensores do DU. Com o presente estudo foi percebido que, em geral, na intenção de proporcionar acessibilidade, foram feitas apenas adaptações estruturais aos espaços que, visivelmente, são apenas facilitadoras de locomoção, encobrindo assim uma necessidade de tomada de atitude abrangente a ser implementada nesses estabelecimentos hoteleiros.

\section{CONSIDERAÇÕES FINAIS}

Ao longo da história, a sociedade vem discriminando os indivíduos com mobilidade reduzida do meio social, principalmente as pessoas com deficiência. Essa discriminação ainda pode ser considerada enraizada nos dias atuais em inúmeros domínios sociais, deixando à margem da sociedade vários indivíduos que têm seus direitos de cidadãos reduzidos por falta de adequação de equipamentos, espaços e ambientes. 


\begin{tabular}{|l|c|c|c|}
\hline \multicolumn{1}{|c|}{ ITENS } & HOTEL A & HOTEL B & HOTEL C \\
\hline $\begin{array}{l}\text { Armário com a parte inferior instalada a 0,30m do } \\
\text { piso deixando o espaço abaixo livre de qualquer } \\
\text { saliência ou obstáculo. }\end{array}$ & & SIM & SIM \\
\hline Janelas com altura acessíveis para cadeirantes & SIM & & SIM \\
\hline Escadas rolantes & & SIM & \\
\hline Elevadores acessíveis & & SIM & SIM \\
\hline Símbolos internacionais de acesso & & & SIM \\
\hline $\begin{array}{l}\text { Controles, comandos e puxadores dentro da altura } \\
\text { de acessibilidade para cadeirantes. }\end{array}$ & SIM & & SIM \\
\hline
\end{tabular}

Fonte: Dados da pesquisa (2014)

Como contraponto dessa realidade, diversas leis vêm sendo instituídas, procurando a inclusão das PMR. Isso se deve porque a cada dia, a sociedade percebe melhor que pessoas com algum tipo de mobilidade reduzida não são sinônimo de limitação, mas de superação e como qualquer indivíduo deve ter seus direitos de cidadãos garantidos.

A conscientização da igualdade dos cidadãos está alicerçada por diversos fatores, entre eles: as comunicações e os transportes que há muito se desenvolveram velozmente; a modificação das necessidades humanas comprovada de forma clara; o desenvolvimento da economia; e a excessiva urbanização com verticalização arquitetônica presente em centenas de milhares de cidades do mundo. Com isso, os seres humanos estão conseguindo mais espaço e conhecimento para desvendar suas diversidades e lutar pela conquista de seus direitos.

Observa-se que a acessibilidade é uma sequência de opções e escolhas de utilização de espaços públicos e privados que correspondem às necessidades de indivíduos com diferentes maneiras de obstáculos de locomoção. A aplicação de produtos, espaços e equipamentos com acessibilidade é necessária para proporcionar condições de utilização com segurança, confiabilidade e autonomia. A acessibilidade é uma conquista social, assegurada pelo direito de ir e vir, ressaltando a cidadania de cada um. Quando um ambiente é edificado acessível a todos, está preparado para proporcionar chances iguais a quem dele fizer uso.

É imprescindível que a hotelaria fique atenta à relevância da presença do público com mobilidade reduzida em seus empreendimentos. Adequações devem ser feitas em seus ambientes, tornando-os verdadeiramente acessíveis para receber todos os tipos de pessoas, com segurança e comodidade. Na atualidade, diversos tipos de cidadãos fazem uso dos equipamentos do trade tu- rístico, dentre eles o grupo de PMR. Dessa forma, os hoteleiros devem ter a consciência da necessidade dessa parcela de clientes; e encarar essa readequação em seus empreendimentos como um diferencial de suma importância, tanto para os seus hotéis, como para a sociedade. O campo da hotelaria deve estar inserido na busca pela inclusão das PMR.

Considera-se que o objetivo geral dessa pesquisa foi atingido pela aplicação do check-list relacionado aos itens de acessibilidade dos hotéis de categoria cinco estrelas da cidade de Fortaleza. Os dois objetivos específicos traçados também foram alcançados, primeiramente quando identificadas as necessidades básicas de uma PMR dentro da hotelaria por meio do levantamento das normas de acessibilidade mais difundidas no Brasil. O último alcance dos objetivos específicos ocorreu quando foram pontuadas a presença ou ausência dos itens necessários para acessibilidade, de acordo com as normas da ABNT e Manual da EMBRATUR, dentro de cada hotel avaliado.

O presente estudo mostrou a existência de leis e normas exigidas por órgãos responsáveis e destacou os direitos que essas pessoas têm em estar não integradas à sociedade, mas sim inclusas. Concluiu-se que nenhum dos hotéis pesquisados apresentava a quantidade mínima de unidades acessíveis exigidas por lei. Ressaltouse ainda que apenas um dos hotéis dispunha, em seus quartos acessíveis, de todos os itens básicos de acessibilidade determinados nos documentos citados. Também não foi constatada, em nenhum dos hotéis, a presença de todos os itens acessíveis nas áreas de acesso comum aos hóspedes.

A partir dos resultados expostos, pode-se concluir que a hotelaria cinco estrelas da cidade de Fortaleza não possui completa acessibilidade para recepcionar hóspedes com mobilidade reduzida. Modificações ainda precisam ser feitas nas estruturas desses hotéis para que 
PANORAMA DA ACESSIBILIDADE NOS HOTÉIS 5 ESTRELAS DE FORTALEZA - CEARÁ

eles possam readequar-se às normas. Faz-se necessário, então, por partes dos hoteleiros, amplificar o compromisso com a questão da acessibilidade, trazendo assim benefícios tanto para a sociedade quanto para os estabelecimentos.

\section{REFERÊNCIAS}

\section{ABNT. ASSOCIAÇÃO BRASILEIRA DE} NORMAS TÉCNICAS (ABNT). Acessibilidade de pessoas portadoras de deficiências a edificações, espaço, mobiliário e equipamentos urbanos: NBR 9050/2015. Rio de Janeiro, 2015.

ALENCAR, A. Acessibilidade na hotelaria: um degrau que faz a diferença. 2011. Revista Hotéis. 18 abr. 2011. Disponível em: <http://www.revistahoteis.com.br/> Acesso em: 11 mar 2017.

BOSSINI, A. B. N. Acessibilidade em obras públicas. Dissertação (Monografia (Especialização em Construção de obras públicas)) — Universidade Federal do Paraná, Curitiba, 2010. 119 f.

BRASIL. Pontos turísticos brasileiros ganharão 14 projetos de acessibilidade. 2013. Ministério do Turismo. Disponível em: <http://www.brasil.gov.br/ turismo/2013/08/> Acesso em: 20 mar 2015.

Estatuto da pessoa com deficiência. 1. ed. Brasília: Senado Federal, Coordenação de edições técnicas, 2015.

Lei de acessibilidade. Decreto 5296. 2016. Disponível em: <http://www.acessibilidadebrasil.org. br/versao_anterior/index.php?itemid=43> Acesso em: 16 mar 2016 .

CARDOSO, A. T.; STRASSBURGES, N. C. A Acessibilidade na Hotelaria de Bento Gonçalves - RS. 2012. Disponível em: <www.ucs.br/ucs/.../ eventos/...tur.../01_18_39_Cardoso_Strassburger> Acesso em: 18 mai 2015.

CARLETTO, A. C.; CAMBIAGHI, S. Desenho Universal: um conceito para todos. 1. ed. São Paulo: Instituto Mara Gabrilli, 2008.

CASTELLI, G. Administração hoteleira. 1. ed. Caxias do Sul: EDUCS, 2003.

EMBRATUR. Manual de recepção e acessibilidade de pessoas portadoras de deficiência a empreendimentos e equipamentos turísticos. Brasília, DF, 1999.
GARCIA, C. C. Sociologia da acessibilidade. 1. ed. Curitiba: IESDE, 2008.

GONZÁLEZ, N. E. K. Hospitalidade e preconceito no turismo. Turismo, Visão e Ação, v. 4, n. 10, p. 91-100, 2002.

GOULART, R. As viagens e o turismo pelas lentes do deficiente físico praticante do esporte adaptado: um estudo de caso. Dissertação (Dissertação de mestrado em Turismo) - Universidade de Caxias do Sul, Caxias do Sul, 2007.

I.SOCIAL. solução em inclusão social.

Dados da deficiência. 2017. Disponível em: <http://isocial.com.br/dados-da-deficiencia.php $>$ Acesso em: 11 mar 2017.

LASHLEY, C. Para um entendimento teórico. In: LASHLEY, C.; MORRISON, A. (Ed.). Em busca da hospitalidade: perspectives para um mundo globalizado. Barueri, SP: Manole, 2004.

LIMA, J. C. F. O ensino profissionalizante como ferramenta para cidadania e inclusão social: o Projeto Mulheres de Fortaleza. Dissertação (Dissertação (Mestrado em Educação)) — Universidad Del Pacífico, Assunção, Paraguai, 2012. 190 f.

\section{ONU. ORGANIZAÇÃO DAS NAÇÕES UNIDAS}

(ONU). Convenção sobre os direitos as pessoas com deficiência comentada. Brasília: Secretaria Especial dos Direitos Humanos. Coordenadoria Nacional para Integração da Pessoa Portadora de Deficiência. Brasília, 2008.

PITA, M. Deficientes representam 24\% da população do Brasil, diz IBGE. São Paulo: [s.n.], 2011. Terra. Disponível em: $<$ http://economia.terra.com.br/terra-da-diversidade/ deficientes-representam-24-da-populacao-do-brasil-diz-ibge, 7258b920548da310VgnCLD200000bbcceb0aRCRD. html>. Acesso em: 11 mar 2017.

SASSAKI, R. K. Acessibilidade: uma chave para a inclusão social. 2004. Disponível em: <http://www.maxwell./10500_3.PDF>. Acesso em: 03 abr 2015.

Inclusão: o paradigma do século 21. Inclusão: revista da educação especial. 2005. Disponível em: <http://portal.mec.gov.br/seesp/arquivos/pdf/ revistainclusao1.pdf $>$. Acesso em: 11 mar 2017.

SILVA, A. C. L. d. Acessibilidade as pessoas portadoras de deficiência aos hotéis de Brasília. 
PANORAMA DA ACESSIBILIDADE NOS HOTÉIS 5 ESTRELAS DE FORTALEZA - CEARÁ

2004. Disponível em: <bdm.unb.br/bitstream/3/2004_

AnaCristinaLopesSilva.pdf>. Acesso em: 13 mar

2015. 